\title{
Morphometry of the Placental Vessels
}

\author{
PETRU BORDEI ${ }^{1}$, LOREDANA STEFANIA SURDU1*, LUCIAN SERBANESCU1, IOAN SORIN TUDORACHE² \\ ${ }^{1}$ University Ovidius of Constanta, Faculty of Medicine, Campus, 1 University Alley, Corp B, 900470, Constanta, Romania \\ ${ }^{2}$ Titu Maiorescu University,Faculty of Medicine, 67A Gheorghe Patrascu Str., 031593, Bucharest, Romania
}

The morphometry of the placental vessels was studied on a number of 51 normal term placentas, using plastic injection (Technovit 7143), followed by sodium hydroxide corrosion. In 51 cases, we found the diameter of the umbilical vein between $6.2-10.5 \mathrm{~mm}$, most commonly, in $54.90 \%$ of cases, finding it between 8.0-8.6 $\mathrm{mm}$. The trunk of the umbilical vein arised from a number of 2-4 branches, most commonly, in $41.18 \%$ of cases, being made of 2 branches. We observed the umbilical arteries on a number of 42 cases. The diameter of the umbilical artery 1, was between 2.5-6.0 mm, most frequently, in $45.24 \%$ of cases, having a diameter between $4.0-4.9 \mathrm{~mm}$. The ratio between the diameter of the umbilical artery 1 and the diameter of the corresponding venous trunk was most commonly between 50.0-58.82\%. The diameter of the umbilical artery 2, was between 3.0-8.5 mm, most frequently, in $53.66 \%$ of cases, having a diameter between 4.0-4.8 $\mathrm{mm}$. The ratio between the diameter of the umbilical artery 2 and the diameter of the corresponding venous trunk, was most commonly between $40.0-46.51 \%$, in one case, the diameter of the umbilical artery 2 was equal to the diameter of the venous trunk. Comparing the diameters of the two umbilical arteries on 41 placentas, we found in $56.10 \%$ of cases, the diameter of the umbilical artery 2 was larger then the diameter of the umbilical artery 1 by $0.2-2.5 \mathrm{~mm}$ and in $39.02 \%$ of cases, the diameter of the umbilical artery 1 was larger then the diameter of the umbilical artery 2 by $0.1-0.9 \mathrm{~mm}$. In $8.20 \%$ of cases the umbilical arteries had the same diameter.

Keywords: placental, vessels, morphometry

Placental vessels are represented by the two umbilical arteries and the umbilical vein, which provides fetalplacental circulation. For [1, 2], placental branches of the umbilical vessels extend to the placental villi. Angiogenesis during placentation is controversial. According to E.W. Dempsey [quoted by 3], the vessels are formed by the aggregation of mesenchymal cells and capillary cavities. Around these tubes are grouped mesenchymal cells and Hofbauer cells. Other authors consider that villous angiogenesis is done by the extension of the umbilicoallantoid vessels, which communicate from the beginning with the villous vessels. Maternal blood is transported to the placenta through the spiral arteries of the uterus [4]. The cotyledons receive 80-100 spiral arteries that cross the basal plate and enter the intervillous spaces, at more or less regular intervals. These spiral arteries have small caliber at the level of their penetration orifice and blood pressure is high at this level. As a result, the blood passes into the blood lakes where all branches of the primary villous trunks are bathed by oxygenated blood. When the pressure decreases, the blood flow returns from the chorial plate to the decidual plate and enters the endometrial veins. On the entire surface of the decidual plate are venous orifices through which the blood is resumed in the maternal circulation [4-6]. On the fetal side the poor oxygenated blood pumped by the fetal heart, is sent in the umbilical arteries, passes through the capillaries of the villous arborescences and returns through the umbilical vein into the fetus. Within the intervillous spaces, exchanges are performed by diffusion with the maternal blood, the oxygen being absorbed and soluble waste eliminated [7]. In its assembly, when the placenta is constituted, the blood lakes contain about $150 \mathrm{ml}$ of blood, which is renewed 3-4 times/ minute. This blood comes in contact with the chorionic villi, whose total surface reaches between $4-14 \mathrm{~m}^{2}$. It should be noted that placental exchanges do not take place at the level of all villosities, but only at the level of those at which the fetal vessels are in close contact with the syncytial membrane that covers them. In these last villi, the syncytium frequently presents a brush border $[4,5,8]$.

\section{Experimental part}

Material and methods

The morphometry of the umbilical vessels was observed on 51 normal term placentas, which, after being collected, were analyzed first from a macro and mesoscopic point of view and then injected with Technovit 4173 (red color for umbilical arteries and blue color for the umbilical vein). The specimens were corroded with sodium hydroxide solution, heated to $70-90^{\circ}$, the corrosion exposure times varying with the size of placentas. Technovit 4173 is a selfpolymerizing synthetic resin based on methyl methacrylate, in powder form. NN dimethyltoluidine $3 \%$ is used as solvent. Measurements were made with the caliper. Besides the diameter, at the level of the umbilical vein, we observed the number of branches that contribute to the formation of the venous trunk, and at the level of the arteries we observed the branches that detach from them, for both types of vessels evaluating the placental territory they serve. There were also recorded the relationships and the trajectory between the venous and arterial branches, as well as the existence of interarterial anastomosis, appreciating its situation and size.

\section{Results and discussions}

In 51 cases, we found the diameter of the umbilical vein between $6.2-10.5 \mathrm{~mm}$, most commonly, in 28 cases (54.90\% of cases) finding it between $8.0-8.6 \mathrm{~mm}$. In the other cases we encountered the following situation: in 17 cases (33.33\% of cases) the veins had a diameter between 9.0-9.6 mm, in 4 cases (7.84\% of cases) the diameter was between $7.0-7.8 \mathrm{~mm}$, and in one case (1.96\% of cases) the venous diameter was $6.2 \mathrm{~mm}$, respectively $10.5 \mathrm{~mm}$. The formation of the umbilical vein trunk was made from a number of 2-4 main branches, most commonly, in 21 cases ( $41.18 \%$ of cases) being made of 2 branches, in the

\footnotetext{
* email: surdudn@yahoo.com
} 
remaining cases being made of 3 venous branches in 18 cases ( $35.29 \%$ of cases), and in 12 cases ( $23.53 \%$ of cases) of 4 venous branches (fig.1).

We studied the umbilical arteries on a number of 42 cases and because they were not always located to the right and left of the venous trunk, we named them the umbilical artery 1 (most commonly located to the right of the venous trunk) and the umbilical artery 2 (most commonly located to the left of the venous trunk). The umbilical artery 2 was observed in a number of 41 cases, because in one case we encountered a single umbilical artery, located to the right of the venous trunk.

We found the diameter of the umbilical artery 1 , between 2.5-6.0 mm, in 19 cases (45.24\% of cases), most commonly, having a diameter between $4.0-4.9 \mathrm{~mm}$; in 15 cases (35.71\% of cases) the arterial diameter was between 3.1-3.9 mm, in 6 cases ( $14.29 \%$ of cases) between $5.0-5.2 \mathrm{~mm}$, and in one case ( $2.38 \%$ of cases) $2.5 \mathrm{~mm}$ (fig. 2), respectively $6 \mathrm{~mm}$.

For these 42 cases we analysed the ratio between the diameter of the umbilical artery 1 and the diameter of the corresponding venous trunk, finding that it represented between $29.07-75.0 \%$ of the venous trunk, most commonly representing between $50.0-58.82 \%$, in 16 cases $(38.10 \%$ of cases). For the rest of the cases, in 11 cases $(26.19 \%$ of cases) the arterial diameter represented $41.05-49.38 \%$ of the venous trunk diameter, in 8 cases (19.05\% of cases) represented $36.26-38.27 \%$, in 4 cases (9.52\% of cases) represented $72.4-75.0 \%$, in 2 cases $(4.76 \%$ of cases) represented $62.0-62.5 \%$, and in one case (2.38\% of cases) represented $29.07 \%$ of the venous trunk.
The diameter of the umbilical artery 2, was between $3.0-8.5 \mathrm{~mm}$, most frequently, in 22 cases ( $53.66 \%$ of cases), with a diameter between $4.0-4.8 \mathrm{~mm}$, in 10 cases $(24.39 \%$ of cases) had a diameter between $3.1-3.9 \mathrm{~mm}$, in 8 cases ( $19.51 \%$ of cases) between $5.0-5.2 \mathrm{~mm}$, and in one case ( $2.44 \%$ of cases) the diameter was $8.5 \mathrm{~mm}$. On the same number of cases we analyzed the ratio between the diameter of the umbilical artery 2 and the diameter of the corresponding venous trunk, finding that it represented between $37.65-75.0 \%$ of the venous trunk, the most commonly representing between $40.0-46.51 \%$, in 17 cases $(41.46 \%$ of cases). For the rest of the cases, in 14 cases (34.15\% of cases) the arterial diameter represented 50.0 $55.56 \%$ of the diameter of the venous trunk, in 4 cases (9.76\% of cases) represented $60.98-62.50 \%$ and $71.43-$ $75.0 \%$, respectively, and in one case represented $37.65 \%$ of the venous trunk. Also in one case, the diameter of the umbilical artery 2 was equal to the diameter of the corresponding venous trunk.

On a number of 41 placentas we compared the diameters of the two umbilical arteries, finding that in 23 cases $(56.10 \%$ of cases), the diameter of the umbilical artery 2 was greater by $0.2-2.5 \mathrm{~mm}$ than the diameter of the umbilical artery 1 , in 16 cases (39.02\% of cases) the diameter of the umbilical artery 1 was greater by 0.1-0.9 $\mathrm{mm}$, and in 2 cases ( $8.20 \%$ of cases), the two umbilical arteries had the same diameter (respectively $4.2 \mathrm{~mm}$ and $5.0 \mathrm{~mm}$ ).

Regarding the diameter of the trunk of the umbilical vein, most commonly it had the value between 8.0-9.9 $\mathrm{mm}$ in $88.23 \%$ of cases, the average value of the venous diameter being $8.11 \mathrm{~mm}$. The extreme values, the

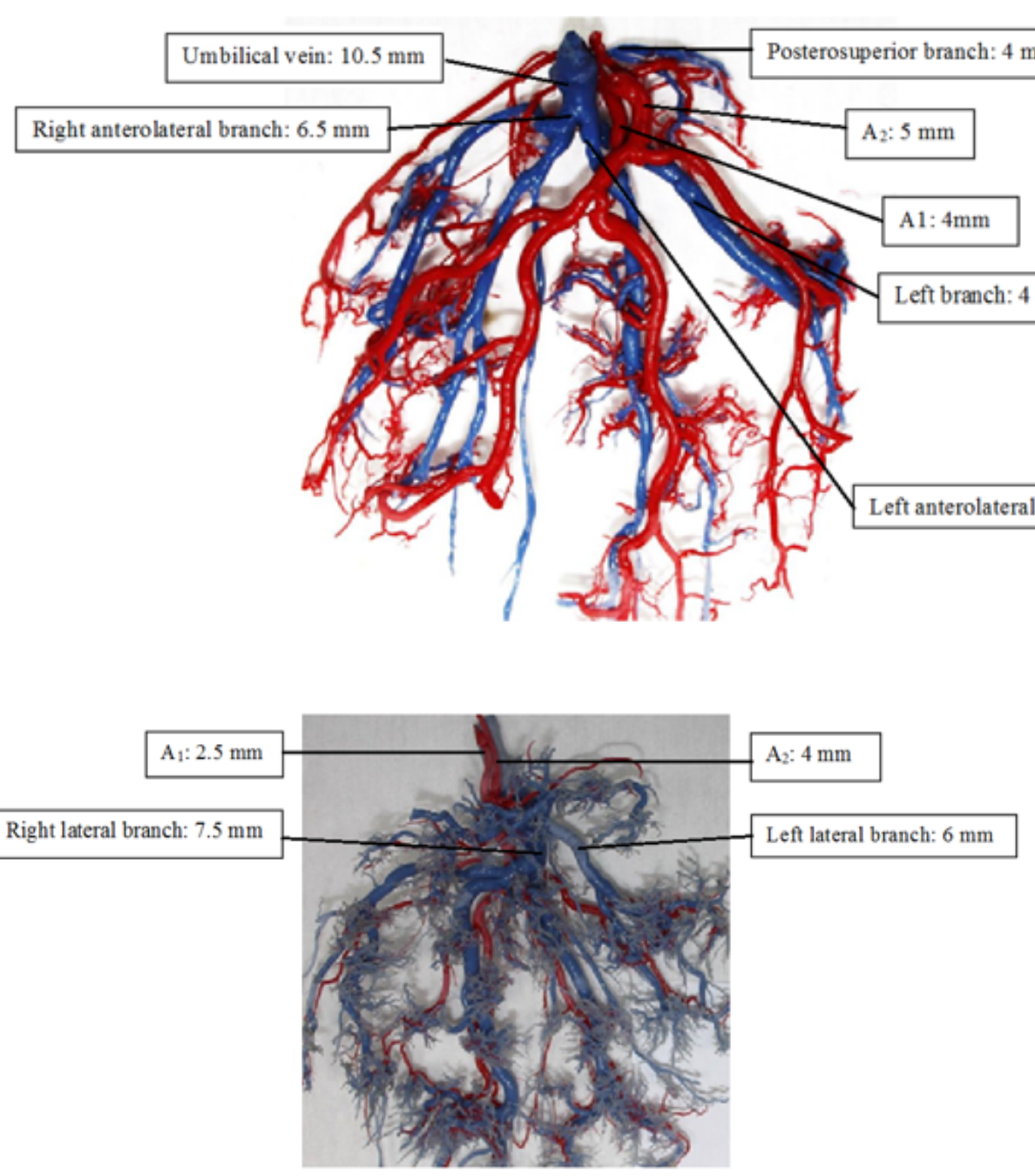

Fig. 1. The umbilical vein has a diameter of $10.5 \mathrm{~mm}$, is disposed paracentrally and formed from 4 main branches; the umbilical artery 1 (Al) has a diameter of $4 \mathrm{~mm}$, representing $38.1 \%$ of the venous caliber; the umbilical artery 2 (A2) has a diameter of $5 \mathrm{~mm}$, representing $47.62 \%$ of the venous caliber

Fig. 2. The umbilical vein has a diameter of $8.6 \mathrm{~mm}$; is formed from 2 main branches, the left lateral branch of $6 \mathrm{~mm}$ and the right lateral branch of $7.5 \mathrm{~mm}$.

The umbilical arteries are located adjacent to the anterolateral right side of the umbilical vein, having a diameter of $2.5 \mathrm{~mm}$ for the umbilical artery 1 (A1) and $4 \mathrm{~mm}$ for the umbilical artery 2 (A2). 


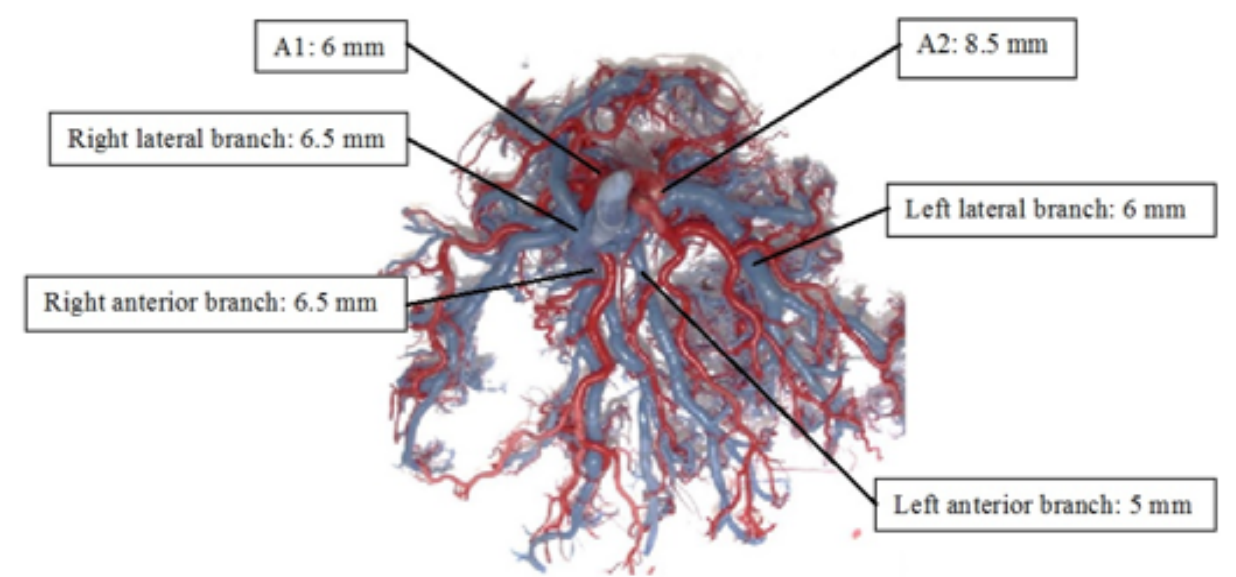

Fig. 3. The umbilical vein has a diameter of $8 \mathrm{~mm}$, being formed from 4 branches: right lateral, with a diameter of $6.5 \mathrm{~mm}$; right anterior with a diameter of $6.5 \mathrm{~mm}$, left anterior with a diameter of $5 \mathrm{~mm}$; left lateral with a diameter of $6 \mathrm{~mm}$. The umbilical artery 1 (A1) is located to the posterolateral right side of the umbilical vein and has a diameter of $6 \mathrm{~mm}$. The umbilical artery 2 (A2) is located laterally to the left side of the umbilical vein and has a diameter of $8.5 \mathrm{~mm}$

minimum of $6.2 \mathrm{~mm}$ and the maximum of $10.5 \mathrm{~mm}$, had been found in a single case. On a number of 83 cases we measured the diameter of the main venous branches that formed the umbilical vein trunk, finding it between 4.0-9.7 $\mathrm{mm}$, with an average value of $5.96 \mathrm{~mm}$. Most commonly the diameter of these venous branches ranged from 5.0 to $7.9 \mathrm{~mm}$ (in $71.49 \%$ of cases) (fig. 3).

We could only compare these diameters with the results obtained by [9] in a study done in 2008, which on 24 cases, finds that in 23 cases $(95.83 \%$ of cases) the diameter of the umbilical vein was between 7.8-9.5 mm, only in one case finding it $6.0 \mathrm{~mm}$. The maximum value $(9.5 \mathrm{~mm})$ was found in one case ( $4.17 \%$ of cases) while in the remaining cases ( $91.67 \%$ of the cases) the values were between $8.0-9.0 \mathrm{~mm}$. [9] finds that the trunk of the umbilical vein is formed from 3-6 main branches (on average 4 branches), while we found 2-4 branches (on average 2.84 branches). We studied the venous diameter in relationship to the place where the umbilical cord inserts into placenta, finding differences between the central and paracentral insertions. We have not encountered cases of velamentous cord insertion. In the central insertion of the umbilical cord, found in 18 cases (36\% of cases), the diameter of the vein was between $7.8-9.1 \mathrm{~mm}$, the average being $8.64 \mathrm{~mm}$. In the paracentral insertion of the umbilical cord found in 32 cases ( $64 \%$ of cases), the diameter of the vein was between $6.2-10.5 \mathrm{~mm}$, the average being 7.76 $\mathrm{mm}$. In paracentrally inserted cords we encountered both the smallest value and the highest value of the venous diameter, the average value of the diameter being less than the average value of the venous diameter in the centrally inserted cords with $0.88 \mathrm{~mm}$. For [9] this difference is only $0.16 \mathrm{~mm}$.

The diameter of the umbilical artery 1 was found most frequently with a value ranging from 3.1 to $4.9 \mathrm{~mm}(80.95 \%$ of cases), the extreme values, the minimum $(2.5 \mathrm{~mm})$ and the maximum $(6.0 \mathrm{~mm})$, have been encountered in one case ( $2.38 \%$ of cases), the average value being 4.19 $\mathrm{mm}$. The diameter of the umbilical artery 1 was smaller than the diameter of the corresponding umbilical vein in all cases. The arterial diameter represents between 29.07$75 \%$ of the venous diameter, most commonly between $36.26-58.82 \%$, the average value being of $48.93 \%$, the minimum value, $29.07 \%$ finding it only in one case $(2.38 \%$ of cases). We studied the arterial diameter in relationship to the place where the umbilical cord inserts into placenta. In central cord insertion, found in 16 cases $(38.10 \%$ of cases), the artery had a diameter between $3.2-5.0 \mathrm{~mm}$, the average being $4.07 \mathrm{~mm}$. In paracentral cord insertion, encountered in 26 cases ( $61.90 \%$ of cases), the artery had a diameter between $2.5-6.5 \mathrm{~mm}$, the average being 4.43 $\mathrm{mm}$. In paracentral cord insertion we encountered both the smallest value and the highest value of the venous diameter, in one case, the average value of the diameter being greater than the average of the arterial diameter in the central cord insertion by $0.36 \mathrm{~mm}$. For [9] this difference was less than $0.25 \mathrm{~mm}$.

The diameter of the umbilical artery 2 was found most frequently with a value ranging between $3.0-5.2 \mathrm{~mm}$ ( $97.56 \%$ of cases), the extreme values, the minimum (3.0 $\mathrm{mm})$ and the maximum $(8.5 \mathrm{~mm})$, have been encountered in one case ( $2.44 \%$ of cases), the average value being 4.48

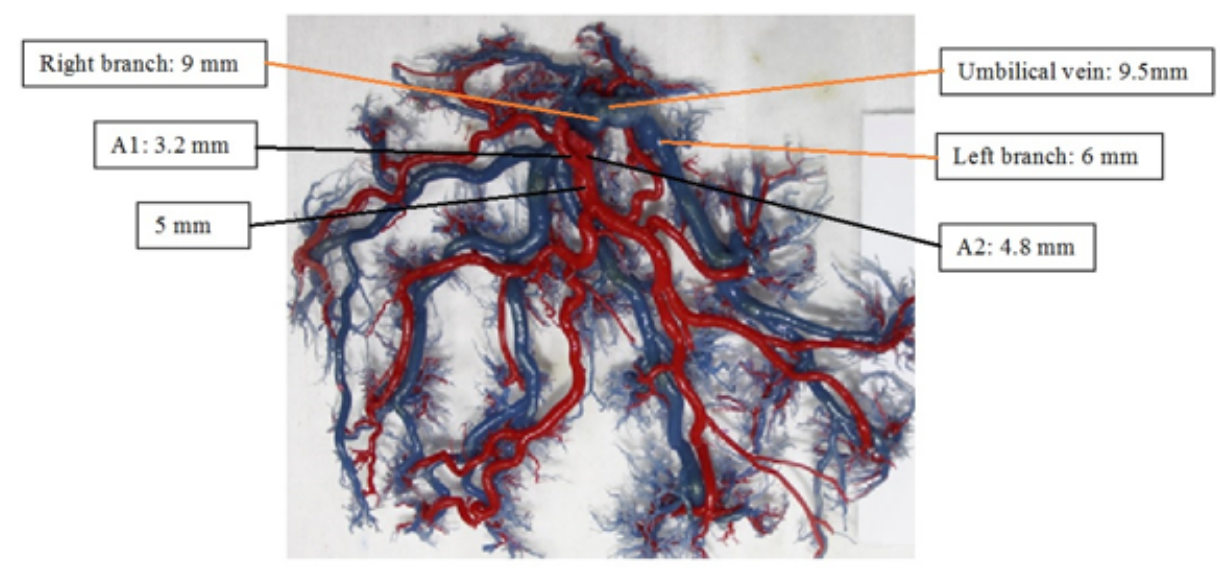

Fig. 4. The umbilical vein, with a diameter of $9.5 \mathrm{~mm}$, is formed from 2 main branches, an unique left branch, with a diameter of $6 \mathrm{~mm}$, and the right one, with a diameter of $9 \mathrm{~mm}$, consisting of 3 branches. Initially there are two umbilical arteries, located to the lateral right side of the umbilical vein: the anterolateral (A1), with a diameter of $3.2 \mathrm{~mm}$ and the left (A2), having a diameter of $4.8 \mathrm{~mm}$. Below the confluence of the two main venous branches, $A 1$ is anastomosed with $A 2$, forming a single umbilical artery, with a diameter of $5 \mathrm{~mm}$, from which all the arterial placental branches will come off. Up to the arterial anastomosis, a posterosuperior branch is detached from A1 
$\mathrm{mm}$. Comparing the diameter of the umbilical artery 2 with the diameter of the corresponding umbilical vein, we found that it was smaller in 40 cases $(97.56 \%$ of cases), representing $37.65-75 \%$ of venous diameter, most commonly, in 31 cases ( $75.61 \%$ of cases) representing between $40.0-55.56 \%$. In only one case ( $2.44 \%$ of cases) the diameter of the umbilical artery 2 was equal to the diameter of the venous trunk ( $8.5 \mathrm{~mm})$. We studied the arterial diameter in relationship to the place where the umbilical cord inserts into placenta. In central cord insertion, found in 16 cases ( $39.02 \%$ of cases), the artery had a diameter of between $3.2-8.5 \mathrm{~mm}$, the average being $4.77 \mathrm{~mm}$. In paracentral cord insertion, encountered in 25 cases ( $60.98 \%$ of cases), the artery had a diameter between 3.0-5.2 $\mathrm{mm}$, the average being $3.95 \mathrm{~mm}$. In paracentral cord insertion we encountered only the smallest value in one case ( $2.44 \%$ of cases), the average value of the diameter being less than the average of the arterial diameter in the central cord insertion by $0.22 \mathrm{~mm}$. [9] found the same length in both cases.

In 3 cases (7.32\% of cases), the two umbilical arteries anastomosed at the entrance to the placenta and after a route of approximately $2-4 \mathrm{~cm}$, form a single umbilical artery from which arise all the intraplacental branches (fig. 4).

\section{Conclusions}

In the literature that I had the opportunity to consult, the data regarding the morphometry of placental vessels are very poor, having the possibility to consult only the PhD thesis of Mr. [9] from 2008, regarding the premature separation of normal placenta inserted, the negative variations in the diameter of the placental vessels may influence the placental detachment. Even if only one of the umbilical arteries is hypoplastic and Hyrtl anastomosis is present, the prognosis of a term pregnancy is reserved. The differences we found between our results and those [9] obtained, were due to the number of cases we worked on. We worked on a double number of placenta compared to [9] and we considered as an independent branch even though its length was small, being a short distance to the confluence.

\section{References}

1. COCHARD, R.L., Atlas d'embriologie humaine de Netter, Ed. Masson, Paris, 2003, p. 40-48.

2. SADLER, T.W., Langman Embriologie medicala, Ed. Med. Callisto, Bucuresti, 2008, p. 93-103.

3. BACALBASA, GHE., BAUa IC, V., Placenta, Ed. Atos, Bucuresti, 2000.

4. CHIRCOR, L., Placenta. In: Embriologie generala, Ed. University Press, Constanka, 2010, p.142-171.

5. LANGMAN, J., SADLER, T.W., Membranes fœtales et placenta. In: Embryologie medicale, edition Pradel, Paris, 1995, p. 108-131.

6. LAZAR, ST. E., Placenta. In: Reproducere -i embriogenezã umanã, Ed. Mirton, Timi-oara, 2000, p. 268-300.

7. DREWS, U., Placenta. In: Atlas de poche d'embryologie. Ed. Medecine- Sciences, Flammarion, Paris, 1994, p. 124-129.

8. CHIRCOR, L., SURDU, L., Placenta. In: Embriologie umanã, Ed. Ex Ponto, Constanta, 2014, p. 151-181.

9. SERBÃNESCU L., Aspecte anatomice, clinice, morfopatologice si terapeutice în cadrul dezlipirii premature de placentã normal inserata, Teza de doctorat, Constanta, 2008

Manuscript received: 18.11 .2019 